\title{
A inconstitucionalidade do manejo do sequestro e do bloqueio de contas da Fazenda Pública como mecanismo satisfativo
}

The unconstitutionality of the management of confiscation and the blocking of Public Treasury accounts as a satisfactory mechanism

La inconstitucionalidad de la gestión del secuestro y el bloqueo de las cuentas del Tesoro como mecanismo satisfactorio

Igor Veloso Ribeiro ${ }^{1}$

Ádrian Viero da Costa ${ }^{2}$

Helena Gomes Nepomuceno Sena ${ }^{3}$

\section{Resumo}

Objetivo: discutir um dos aspectos do recente da judicialização da saúde no Brasil, qual seja, o crescente uso do sequestro e bloqueio de contas da Fazenda Pública pelo Poder Judiciário como mecanismo satisfativo do acesso privilegiado à saúde, inobstante sua duvidosa constitucionalidade. Metodologia: revisão bibliográfica e documental; e quanto aos objetivos, é explicativa e descritiva. Conclusão: o Poder Judiciário não se compreende como um agente sob o jugo dos princípios que norteiam o Sistema Único de Saúde (SUS); outrossim profere decisões automatizadas, açambarcando o sistema e desconsiderando demais normas constitucionais de direito público, tais como o regime de execução próprio, o regime de precatórios e as normas de planejamento e orçamento públicos.

Palavras-chave: Judicialização da saúde. Integralidade em saúde. Universalização.

\begin{abstract}
Objective: to discuss one of the aspects of the health's judicialization in Brazil, the increasing use of the confiscation and blocking of Public Treasury by the Judiciary, as a satisfactory mechanism of privileged access to health, however its questionable constitutionality. Methodology: bibliographic and documentary review; and about the objectives, it is explanatory and descriptive. Conclusion: the Judiciary does not understand itself as an agent under two guiding principles or the Unified Health System; overcoming decisions made and automated by adopting the system and disregarding other constitutional norms of public
\end{abstract}

\footnotetext{
${ }^{1}$ Mestrando profissional interdisciplinar em Direitos Humanos e Desenvolvimento da Justiça pela Universidade Federal de Rondônia (DHJUS/Unir/Emeron); bacharel em Direito pelo Instituto Camilo Filho (ICF); procurador do Estado de Rondônia da diretoria jurídica da Secretaria de Estado da Saúde do Estado de Rondônia (PGE/Dijur/Sesau/RO). Advogado. Porto Velho, Rondônia, Brasil. E-mail: igorvelosor@gmail.com

${ }^{2}$ Especialista em Direito Penal e Processual Penal pela Fundação Escola Superior do Ministério Público; especialista em Direito Ambiental Urbano pela Universidade Federal do Mato Grosso; bacharel em Direito pela Universidade Estadual de Mato Grosso do Sul; delegada de polícia do Estado de Rondônia na Delegacia Especializada na Proteção à Criança e ao Adolescente, Porto Velho, Rondônia, Brasil. E-mail: adrianviero@gmail.com.

${ }^{3}$ Bacharel em Direito pela Faculdade Interamericana de Porto Velho, pós-graduanda lato sensu em Direito Civil e Processual Civil pela Faculdade Católica de Rondônia; advogada, Porto Velho, Rondônia, Brasil. E-mail: helenassena@gmail.com
} 
direction, as well as the regime of self-execution, or precautionary regime and the norms of public planning and organization.

Keywords: Health's Judicialization. Integrality in health. Universalization.

\section{Resumen}

Objetivo: discutir uno de los aspectos de la reciente judicialización de la salud en Brasil, a saber, el uso cada vez mayor del secuestro y bloqueo de cuentas de Finanzas Públicas por parte del poder judicial como un mecanismo satisfactorio para el acceso privilegiado a la salud, a pesar de su dudosa constitucionalidad. Metodología: revisión bibliográfica y documental; y en cuanto a los objetivos, es explicativo y descriptivo. Conclusión: el poder judicial no se entiende como un agente bajo el yugo de los principios que guían el Sistema Único de Salud; También toma decisiones automatizadas, atesorando el sistema y haciendo caso omiso de otras normas constitucionales de derecho público, como su propio régimen de ejecución, el régimen precautorio y las normas de planificación y presupuesto público.

Palabras-Ilave: Judicialización de la salud. Integralidad en salud. Universalización.

\section{Introdução}

A Constituição da República Federativa do Brasil (CRFB) de 1988 inaugurou um novo tempo para a saúde pública brasileira. A política em saúde foi erigida à máxima constitucional como uma forma de política social, evidenciando o acesso à saúde como um direito inerente à própria cidadania. (1)

A conformação da previdência, da saúde e da assistência social como partes integrantes da seguridade social alinha e sedimenta a ideia de direitos sociais universais, que, por sua vez, estão umbilicalmente relacionados com a cidadania, antes restritos à população beneficiária da previdência (2) (3).

Sobre o tema, Fleury e Ouverney ensinam:

O novo padrão constitucional da política social caracteriza-se pela universalidade na cobertura, o reconhecimento dos direitos sociais, a afirmação do dever do Estado, a subordinação das práticas privadas à regulação em função da relevância pública das ações e serviços nessas áreas, uma perspectiva 'publicista' de co-gestão (sic) governo/sociedade, um arranjo organizacional descentralizado (2) (3).

Na dicção dos arts. 6 e 196 da Lex Superior, a saúde passou a ser "direito de todos e dever do Estado", fato que per si reorientou não só a Administração Pública, mas trouxe para o universo jurídico-constitucional um debate que antes se dava apenas em âmbito político e técnico (4).

Tal mudança de paradigma social, político e jurídico trouxe em seu bojo o desafio de 
ofertar assistência à saúde, em suas dimensões de promoção, proteção e recuperação a uma população que hoje supera 210 milhões de pessoas, em um território de dimensões continentais, com inúmeras particularidades regionais, inserido num regime democrático de Direito e participativo (5).

Numa perspectiva holística, o legislador constituinte não se limitou em garantir o direito aos serviços de saúde. Com efeito, a CRFB de 1988, reconheceu as diretrizes da Conferência Internacional sobre Cuidados Primários de Saúde, capitaneada pela Organização Mundial da Saúde, que aconteceu em Alma-Ata, na República do Cazaquistão, em 1978, expressava "a necessidade de ação urgente de todos os governos, de todos os que trabalham nos campos da saúde e do desenvolvimento e da comunidade mundial para promover a saúde de todos os povos do mundo" (6).

A Declaração de Alma-Ata dispõe que:

A saúde - estado de completo bem- estar físico, mental e social, e não simplesmente a ausência de doença ou enfermidade - é um direito humano fundamental, e que a consecução do mais alto nível possível de saúde é a mais importante meta social mundial, cuja realização requer a ação de muitos outros setores sociais e econômicos, além do setor saúde (6).

É mister anotar que, em contraponto à amplíssima garantia à saúde, o Poder Constituinte originário estabeleceu que tal direito seria realizado através de "políticas sociais e econômicas" garantido o "acesso universal e igualitário às ações e serviços" (1).

O Brasil, embebido pelos ideais do bem-estar social e da social democracia, estabeleceu um formato de política que reflete um projeto solidário de nação, para o qual o direito à saúde é um bem indissociável ao direito de cidadania. Para a concretização desses direitos, por mandamento constitucional, foi estabelecido que se daria por meio das políticas públicas em saúde, observados a universalidade e a integralidade (7).

No Sistema Único de Saúde (SUS), a universalidade informa que todos os brasileiros tenham acesso isonômico aos serviços de saúde e suas respectivas ações. $O$ acesso igualitário, compreendido como equidade, vez que proporciona a concreção da justiça, com a oferta de serviços, direcionada a um grupo ou categoria que necessitem de especial intervenção. $\mathrm{E}$ a integralidade que reforça a interseção setorial e a construção de uma nova governança da gestão de políticas públicas (7). Entrementes, a efetividade de uma política de saúde desse feitio será quanto maior ou menor, a depender da prevalência do projeto 
social, na relação das forças sociais. Ou se compreende que a universalidade e integralidade do acesso devem ser lidos através de lentes coletivas, ou se privilegia o acesso de alguns em detrimento de muitos, uma vez que mesmo que exista previsão de acesso universal e igualitário do direito à saúde, não pode este ser concebido de forma ilimitada, irrestrita e irracional pelo individuo contra o Estado (8).

É imperioso que atentemos para o fato de que, ao se definir uma política pública em saúde, se define um padrão civilizatório e um modelo de sociedade desejável. Não se desconsidera, todavia, que a política em saúde está em constante transformação, vez que está constantemente envolvida pelas lutas e enfrentamentos de diferentes movimentos sociais, no processo de formação, estabilização e confrontação dos padrões hegemônicos de cada sociedade (8).

Para Fleury e Ouverney, concepções sobre a vida, o bem-estar, a saúde, a cidadania, a cultura, a educação e os bens públicos, em geral são constantemente atualizados e ganham novos significados a partir de sua articulação aos diferentes projetos de poder (3).

É nesse contexto que o Poder Judiciário tem sido chamado para dizer o Direito. Diante da constitucionalização do direito à saúde, duas searas técnicas distintas iniciaram um diálogo muitas vezes conflitante (8).

A partir do fim da década de 1990, tais discussões vêm se aprofundando e batendo à porta do Poder Judiciário, revelando em larga medida uma enorme confusão entre os operadores do direito e técnicos da saúde pública sobre o que seria o próprio direito à saúde.

O Poder Judiciário, a despeito da vedação de incursão no mérito dos atos administrativos (conveniência/oportunidade), tem exercido controle acerca da execução das políticas públicas em saúde, todavia tem desconsiderado sistematicamente a organização dos serviços, os conhecimentos e práticas de trabalhadores de saúde e as políticas governamentais com participação popular, partindo da premissa de que a saúde e a própria vida foram erigidas à máxima categoria de proteção constitucional, é dizer, direitos fundamentais (4) (9) (10).

Sob o bastião da força normativa da Constituição, o Poder Judiciário ignora o problema da escassez de recursos, esquivando-se de reconhecer que o direito à saúde, nesse contexto, é necessariamente limitado, e não absoluto. Tal cenário, em determinados circunstâncias, acaba por privilegiar o direito individual à custa dos da coletividade usuária 
do SUS, em ofensa ao princípio da isonomia e da eficiência (11). Cumpre registrar a maioria das ações que estão judicializadas pleiteiam por procedimentos médicos específicos e/ou fornecimento de determinado medicamento. Xavier revela que a maioria das demandas que estão no Judiciário envolve a reivindicação de "um tratamento de valor exorbitante, de tecnologia ainda não avaliada pela Anvisa, que é propagandeado como curativo e que, em verdade, pouco se diferencia dos já oferecidos pelo SUS" (6).

O Poder Judiciário, desconsiderando uma série de fatores sociais, econômicos, ambientais e biológicos inter-relacionados determinantes para o próprio alcance do sentido constitucional do que seja saúde, a reduz e a entende isoladamente apenas sob o estreito prisma da assistência médico-farmacêutica (4).

Ao agir assim, o Poder Judiciário despreza que a atenção à saúde depende de políticas multissetoriais abrangentes que vão muito além dos serviços médicos e do fornecimento de medicamentos. Profere decisões que contrariam a aplicabilidade da política existente, bem como, no caso de não haver uma política definida, não analisa a viabilidade em estabelecê-la dentro dos critérios construídos com fundamento na política pública Protocolos Clínicos e Diretrizes Terapêuticas (PCDT), utilizando-se da medicina baseada em evidências (MBE) (13).

Para Fleury e Ouverney (3), ao atuar em contrariedade às políticas do SUS, o Poder Judiciário põe em risco o próprio sistema:

Assim, uma coalizão política nacional que favoreça a noção da saúde como um bem que deva ser oferecido pelo mercado e apropriado individualmente não oferece um ambiente fértil para a expansão da política universal. Coalizões desse tipo irão restringir os recursos governamentais para o financiamento dos gastos públicos em saúde e irão tentar reduzir os serviços oferecidos pelo Estado a um mínimo possível, bem como tentar restringir o acesso a esses serviços a uma determinada parcela da população (3).

O objetivo deste artigo é discutir um dos aspectos do fenômeno da judicialização da saúde no Brasil, que é o crescente uso do sequestro e bloqueio de contas da Fazenda Pública pelo Poder Judiciário como mecanismo satisfativo do acesso privilegiado à saúde, inobstante sua duvidosa constitucionalidade.

\section{Metodologia}

A metodologia utilizada é bibliográfica e documental; e, quanto aos objetivos, é 
explicativa e descritiva.

\section{O acesso à saúde por meio do Poder Judiciário}

Assegura a CRFB o direito universal à saúde e o acesso à Justiça. Não por acaso, recebeu a alcunha de Constituição Cidadã, justamente porque foi promulgada durante o processo de redemocratização do Brasil, refletindo os anseios da sociedade após 21 anos de regime ditatorial militar e consagrando numerosos avanços e garantias sociais. Reposicionou o cidadão como prioridade absoluta do Estado e assegurou que todo o poder apenas seria legítimo se sufragado através da democracia (1).

Ainda no campo de direitos sociais e garantias fundamentais, a Carta Magna, em seu art. $5^{\circ}$ e incisos, consagra o livre acesso à justiça, resguardando a todos a prerrogativa de defender seus direitos, inclusive contra o Estado, com assistência judiciária gratuita, em caso de comprovada hipossuficiência (1).

É neste cenário de garantias e direitos sociais amplamente cobertos pelo manto da Constituição, com a separação dos Poderes absolutamente independentes entre si, que o Poder Executivo encontra barreiras para efetivar o acesso universal e equânime à saúde $(14)$.

Dentre as maiores problemáticas que geram a deficiência dos serviços públicos de saúdes, a mais notória delas é o subfinanciamento. Há que se considerar também a falta de planejamento, a instabilidade política e a má gestão dos já escassos recursos, além da distribuição desigual deles e a desigualdade social, que torna ainda mais difícil a efetivação dos atendimentos de saúde em determinadas regiões do Brasil.

$\mathrm{O}$ acesso à justiça é princípio constitucional, previsto no art. 5ำ XXXV, que proclama: “a lei não excluirá da apreciação do Poder Judiciário lesão ou ameaça a direito” (1). É também denominado como o princípio da inafastabilidade do controle jurisdicional, ou seja, é uma garantia a todo aquele que se sentir lesado ou na iminência de sofrer alguma lesão, poder recorrer ao Estado-Juiz para ver seus direitos protegidos (1) (15). O acesso à justiça é direito fundamental da pessoa humana, à luz da Declaração de Direitos Humanos de 1948, que trouxe em seu art. 8ํㅜ o direito de todo ser humano de receber proteção contra atos que violam direitos seus reconhecidos por lei. Em igual sentido, preconiza a Convenção Americana de Direitos Humanos de 1969, em seu art. 25, bem como o art. 14 do Pacto 
Internacional das Nações Unidas sobre os Direitos Civis e Políticos (16) (17).

Todos esses dispositivos parecem corroborar e reforçar a ideia de acesso à justiça como o acesso Poder Judiciário, todavia Cappelletti e Garth dão novo sentido ao acesso à justiça, ampliando sua concepção:

O novo enfoque de acesso à Justiça, no entanto, tem alcance muito mais amplo. Essa "terceira onda" de reforma inclui a advocacia, judicial ou extrajudicial, seja por meio de advogados particulares ou públicos, mas vai além. Ela centra sua atenção no conjunto geral de instituições e mecanismos, pessoas e procedimentos utilizados para processar e mesmo prevenir disputas nas sociedades modernas. Nós o denominamos "o enfoque do acesso à Justiça" por sua abrangência. Seu método não consiste em abandonar as técnicas das duas primeiras ondas de reforma, mas em tratálas como apenas algumas de uma série de possibilidades para melhorar o acesso (18).

Tal perspectiva compreende que o acesso à justiça não se resume ao acesso ao Poder Judiciário, mas é, a respeito do conjunto de esforços coletivos das instituições e pessoas, dos mecanismos e procedimentos, voltado para a materialização dos direitos das pessoas da forma mais célere e desburocratizada possível. É a acepção de que uma ordem jurídica justa, com instituições públicas funcionando da maneira adequada é também acesso à justiça (18) (19).

Alcança-se a justiça quando o cidadão acessa instituições estatais competentes, e não somente mediante uma decisão judicial favorável, máxime, em uma sociedade desigual, em que o ingresso ao Judiciário é privilégio. Com efeito, a efetividade e a justeza de decisões judiciais que determinam prestações sanitárias individualmente são questionáveis, na medida em que amparam somente a minoria da população que logrou êxito em acessar o Judiciário. Em um país com um enorme número de pessoas que vivem em condições de pobreza e miséria, é temerário supor que todos possuem as mesmas condições fáticas para postular em juízo. Nessa esteira, tem-se que as demandas individuais salvaguardam a parcela minoritária da população que possui mais informações e melhores condições de acesso ao Poder Judiciário, todavia, não reverbera como benefício à coletividade, de modo que a parcela mais vulnerável permanece desassistida, de saúde e de justiça (20) (21).

Tendo em vista o ideal de uma sociedade justa e igualitária, pondera-se em qual medida a excessiva judicialização dos serviços públicos de saúde é positiva e reflete os interesses da coletividade e da macrojustiça. Quando as decisões judiciais desconsideram 
o planejamento coletivo em favor da perspectiva individual, isso pode significar o retardamento de outros pacientes que aguardam atendimento regular no SUS, dentro das diretrizes e protocolos estabelecidos em favor daqueles que obtiveram êxito em acessar o Judiciário (21).

\section{O devido processo legal contra a Fazenda Pública}

São três as espécies de tutela jurisdicional que o Estado coloca ao alcance do jurisdicionado com o fito de solucionar litígios fundados em direitos materiais controvertidos: o conhecimento, a execução e a cautela (22).

O processo de conhecimento é a fase processual em que a tutela jurisdicional tem como objetivo o reconhecimento de um direito, e deve se encerrar com decisão de mérito, que julga procedente ou improcedente o objeto postulado (22).

A tutela executiva é a atuação do juízo no sentido de satisfazer o direito que foi por ele reconhecido, e a única forma de exaurimento possível é a declaração de satisfação do credor, sendo atípico desfecho diverso. Na fase de cumprimento de sentença, o objetivo é a satisfação do próprio direito, e a sentença prolatada passa a ser título judicial do agora credor, e não resta ao devedor senão o cumprimento da sentença (23) (24).

No processo de conhecimento, culminando em sentença que determina obrigação de pagar quantia certa, quedando-se inerte o devedor, a parte credora provoca o cumprimento de sentença, fase em que o juiz promoverá as ações necessárias para que o crédito seja satisfeito, se não de maneira voluntária, por todos os meios em direitos admitidos (23).

Iniciada a fase de cumprimento de sentença envolvendo somente particulares, se o executado, devidamente intimado, não promover o adimplemento da obrigação no prazo legal, o CPC dispõe sobre os meios que o juízo pode utilizar para que o exequente obtenha a satisfação de seu crédito e autoriza, em seu art. 831, que sejam penhorados tantos bens quanto sejam necessários para a satisfação integral do crédito (25).

Uma vez bloqueado o valor necessário para a integral satisfação do crédito, abre-se novamente o prazo para a parte executada impugnar o valor penhorado, de modo que havendo inconsistência na quantia penhorada, deve o executado argui-la em juízo, para que este proceda com nova análise sobre os fatos alegados. Sendo assim, a quantia bloqueada somente será liberada ao credor após examinadas e superadas as razões da impugnação 
do devedor (25).

Não obstante tais procedimentos, o Código de Processo Civil (CPC) dispõe que o cumprimento de sentença ocorrerá de forma diferenciada quando a parte executada for a Fazenda Pública, em virtude do art. 100 da Constituição, que preconiza:

Art. 100 Os pagamentos devidos pelas Fazendas Públicas Federal, Estaduais, Distrital e Municipais, em virtude de sentença judiciária, far-se-ão exclusivamente na ordem cronológica de apresentação dos precatórios e à conta dos créditos respectivos, proibida a designação de casos ou de pessoas nas dotações orçamentárias e nos créditos adicionais abertos para este fim (1).

Portanto, não é admitida penhora e expropriação dos bens da Fazenda Pública, de modo que o pagamento do crédito devido por ela deve ser realizado por meio de ofícios requisitórios, ou seja, por meio de precatórios judiciais ou por requisição de pequeno valor, necessariamente, observada a ordem cronológica de apresentação (25).O cumprimento de sentença de pagar quantia certa contra a Fazenda Pública possui procedimentos diferentes, de acordo com o CPC, em virtude dos princípios que regulam a Administração Pública, entre eles a continuidade dos serviços públicos e a indisponibilidade dos bens públicos, bem como a isonomia no pagamento a ser realizado (26).

O constituinte e o legislador, ao imporem regimes especiais para a execução em face da Fazenda Pública, não têm o fito de privilegiar esta em detrimento de seus credores. Ao contrário, visam salvaguardar o bem público, garantindo que o pagamento ocorra por meios legais e éticos, em observância aos princípios encartados na cabeça do art. 37 da Magna Carta (1).

O CPC prescreve ainda que a Fazenda seja intimada para impugnar a execução no prazo de 30 dias. Não havendo impugnação ou sendo ela rejeitada, o presidente do tribunal competente expedirá o precatório, ou o juiz competente ordenará, à autoridade competente do ente público, o pagamento de pequeno valor, a ser realizado no prazo de dois meses (25).

As decisões judiciais que determinam bloqueio nas contas públicas não encontram amparo legal outro senão a construção jurisprudencial. Tais decisões afrontam ao sistema processual vigente e, mais do que isso, violam preceitos constitucionais, geram insegurança jurídica, ferem a isonomia e causam prejuízos à sociedade, na medida em que assegura o 
direito de poucos em detrimento dos direitos de muitos. Neste sentido, Abelha ensina:

\begin{abstract}
É político-constitucional a razão pela qual se impedem "a penhora e a expropriação" dos bens da Fazenda Pública. Cabe ao legislador definir sobre a alienação dos bens públicos, e uma eventual "expropriação" feita pelo "Poder Judiciário" feriria o princípio da legalidade, podendo causar um choque de funções entre os Poderes do Estado (24).
\end{abstract}

As sentenças ou decisões liminares que concedem medicamentos ou tratamentos mesmo em face da demonstração, pelo Estado, de que o procedimento ou medicamento postulado não faz parte das diretrizes e programas do sistema público de saúde fundamentam-se no art. 196 da CRFB, que preconiza o dever do Estado de promover o direito à saúde, e ignoram a segunda parte do referido postulado, que estabelece que a promoção se dará por meio de políticas sociais e econômicos (1).

O crescente bloqueio em contas particulares de servidores no exercício de sua função pública mais parece uma distopia do Poder Judiciário que desconsidera o direito em sua integralidade. Ao vestir antolhos, não observa o fato social em perspectiva, uma vez que se trata de constrição patrimonial de pessoa que não figura na lide. Se a demanda é proposta contra o Estado, é questionável a decisão que indisponibiliza bens pessoais do gestor ou de qualquer outro agente público que preste seus serviços naquele órgão, ainda que como meio coercitivo. Há casos em que o magistrado determina a indisponibilidade de valores na conta pessoal de novos gestores em razão de demandas judiciais anteriores à sua posse no cargo (27) (28).O texto constitucional preconiza que nenhuma pena passará da pessoa do condenado (art. 5, XLV), sendo essa uma máxima do direito penal (1). Se a ultima ratio estatal considera que as personalidades jurídicas e naturais devem ser respeitadas, parece teratológico conceber que pessoas no exercício profissional regular de direito possam ter seu patrimônio ameaçado por não executarem uma ordem, mesmo que judicial, quando esta não guarda logicidade sistemática ou é flagrantemente ilegal - nos casos em que desconsidera os protocolos terapêuticos e regras de incorporação de novas tecnologias no SUS). Parecem ser coagidos a exercer suas atribuições ao alvedrio do próprio comando constitucional que determina que o acesso ao SUS deve ser universal e integral, desde que por meio de suas políticas públicas (1) (29).

De acordo que os dados do Tribunal de Contas da União (TCU) (17), o impacto da judicialização nas contas dos entes federativos é axiomático: de 70 milhões de reais, em 
2008, havendo um salto para 1 bilhão de reais, em 2015. No Estado de Rondônia (RO), por exemplo, no ano de 2015, foram sequestrados mais de cinco milhões de reais das contas públicas em litígios de saúde, valor esse que seria investido em políticas públicas de assistência de saúde (30) (31).

Numa análise perfunctória, percebe-se que as sentenças exaradas não apenas se equivocam no tocante às premissas da efetivação do direito à saúde e dos vetores do SUS - universalidade e integralidade -, como também na forma de dar cumprimento a essas decisões, com o sequestro e o bloqueio de valores.

É forçoso reconhecer que o Estado tem por disposição do art. 196, da Constitucional Federal e por postulado infraconstitucional o dever de formular e executar as políticas sociais

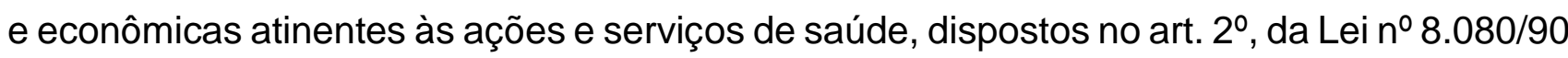
(1) (29).

O acesso equânime às ações e aos serviços de saúde deve estar em consonância com o planejamento integrado, com a apreciação da gravidade do risco individual e coletivo, (Lei oㅡ 8.080/90), as especificidades dos sujeitos que gozam de proteção especial, sem olvidar a orientação dos fluxos das ações e serviços de saúde (arts. 11 a 13, do Decreto no 7.508/2011) (29) (32).

Para além das regras constitucionais de orçamento e finanças, o SUS foi desenhado em total respeito aos aspectos democráticos, consagrando, pela primeira vez no ordenamento patrício, os postulados da participação popular, que foram positivados no corpo da Lex Superior. Tudo em consonância com os direitos fundamentais de acesso à informação, máxime a administrativa (art. 5ำ VIX, XXXIII, CRFB), o direito de petição e de certidões em repartições públicas (art. 5ํ, XXXIV), além da garantia do devido processo legal na esfera administrativa (art. 5, LV, CRFB) (1). Igor Veloso Ribeiro ensina que a efetivação da participação popular é um mecanismo de fortalecimento da democracia. Nessa senda, bebe dos conceitos sociológicos e reconhece no controle social um caráter positivo de devir democrático, assim entendido como a atuação dos grupos sociais (e.g. sociedade civil organizada), "uma das vias de participação democrática no controle das ações do Estado e dos gestores públicos" (33).Sobre o controle social, a participação popular positivada e a formação no planejamento das ações estatais obtempera: 
Partindo-se da concepção de democracia representativa, o processo de planejamento, execução e controle administrativos do Estado poderia ser encarado com a seguinte sequência e etapas: anseios da sociedade, proposta do candidato/gestor público, eleição/designação, planejamento (Plano Plurianual, Lei de Diretrizes Orçamentárias e Lei Orçamentária Anual), execução, controle e atuação por meio das vias democráticas. Nesse processo, a sociedade aparece com função de alimentação do ciclo com as informações que permitam o ajuste, a correção e os novos planejamentos.

O controle social pressupõe um avanço na construção de uma sociedade democrática determinando alterações profundas nas formas de relação do aparelho do Estado com o cidadão (33).

É a cogestão ou gestão democrática positivada. Os arts. 204, II e 194, VII, da CRFB preveem a participação na formulação de política e controle de ações na área de assistência e seguridade social. Já no art. 198, III, existe a previsão da participação da comunidade como diretriz precípua do SUS (1).

O art. 36 da Lei no 8.080/90 determina que o processo de planejamento e orçamento do SUS será ascendente, do nível local até o federal, ouvidos seus órgãos deliberativos (conselhos de saúde e participação popular), compatibilizando-se as necessidades da política de saúde com a disponibilidade de recursos em planos de saúde dos Municípios, dos Estados, do Distrito Federal (DF) e da União. Dispõe ainda que os planos de saúde serão base das atividades e programações de cada nível de direção do SUS, e seu financiamento deve ser previsto na respectiva proposta orçamentária (29).

Desconsiderar esse viés participativo que informa o planejamento e o orçamento é malferir o próprio regime democrático, vez que é dever da Administração Pública observar a lei orçamentária anual (arts. 6ํㅜ 30, 167 e 196, da CRFB), além de ser um claro contraponto entre o direito fundamental à saúde (21).

Com efeito, o tema se apresenta bastante controverso, porquanto estão em xeque os direitos mais basilares e caros à sociedade: saúde, vida e dignidade da pessoa humana, o que faz com o que o Poder Judiciário, na ânsia de conferir-Ihes máxima efetividade, atendendo o mandamus do Constituinte originário, valha-se da concessão desenfreada e de artifícios, como sequestro e bloqueio, que contrariam o regime publicista (precatório/planejamento/orçamento).

A judicialização da saúde afeta as contas públicas por meio dos bloqueios e sequestros judiciais, expedientes que, conforme informações do TCU, geralmente são feitos na conta única do ente estatal. Todavia, há casos de bloqueios que se deram em contas de 
convênios. Tais expedientes inviabilizam a utilização do recurso bloqueado ou, no caso da tutela satisfativa, esvaem uma monta que dificilmente poderá ser reavido por qualquer razão ou forma (32).

Certo é que os princípios, a partir da ideia de neoconstitucionalismo (24), tiveram sua importância reconhecida, o que somado ao papel central da Constituição, do qual não se arreda o direito processual, acarretam a tutela constitucional do processo, nas linhas mestras de Luiz Guilherme Marinoni (25), devendo conformar as medidas adotadas em seus contornos. Soma-se a isso, em um país de democracia incipiente, uma classe política em grande medida desacreditada, a judicialização intensa (art. 5ํ, XXX, CRFB) e o ativismo judicial que cresce a "olhos vistos" (35) (36) (37).

Por melhor caminho que possa soar a lide e, em certo ponto, inevitável, o ativismo judicial deve ser ponderado e controlado, sem que isso de per si, seja considerado uma afronta às garantias dos magistrados, porquanto o sistema de freios e contrapesos não foi abolido (37).

Fato é que nos distanciamos das premissas alinhavadas do conceito pós-revolução francesa bouche de la $\mathrm{loi}^{4}$, pois o magistrado deixou de ser apenas um arauto das disposições legais e aproxima-se daquilo que o jurista Lênio Streck entende por "dono da lei", ou seja, o intérprete não se apresenta mais como mero aplicador do direito, pois em muitas oportunidades passam a deixar de aplicar a lei, além de integrar as lacunas deixadas pela lei, em detrimento do apego a outras fontes que fundamente a "melhor decisão" (38).

Destacamos que essas divagações aparentes vão ao encontro do questionamento de ponderação de princípios que fundamenta o desrespeito ao rito próprio cabível à Administração Pública, de modo a fundamentar as decisões que determinam bloqueios e sequestros de verbas públicas, com alto grau de prodigalidade, a ponto de atingir os mandatários do Estado, até mesmo servidores de carreira que se veem repentinamente atingidos por decisões judiciais que Ihes afeta, por apenas representarem o Executivo, fundamentadas muitas das vezes em princípios gerais interpretados a sorte dos ventos, em clara inobservância ao que preceitua a legislação vigente (art. 28, do Decreto-Lei no 4.657, de 4 de setembro de 1942) (39).

${ }^{4}$ Os insurgentes da Revolução Francesa, de 1789, na ânsia por quebrar o modelo social pré-Revolução, atribuíram a figura de bouche de la loi, ou seja, os juízes deveriam se circunscrever à aplicação do Código Civil. 
Nesse sentido, esclarece Streck:

Esse panprincipiologismo faz com que, a pretexto de aplicar princípios constitucionais, haja uma proliferação descontrolada de enunciados para resolver determinados problemas concretos, muitas vezes ao alvedrio da própria Constituição (40).

Desta maneira, salutar rememorar que as contas públicas são geridas pelo Poder Executivo, o qual por disposição constitucional é independente, não cabendo ao Poder Judiciário sobrepor-se aos demais, sob o manto da integridade, imparcialidade e justiça e passar a decidir como se executa o orçamento, pelo menos não da forma como estamos vivenciando hodiernamente em terra brasilis.

Não estamos alheios aos argumentos encampados pelo Superior Tribunal de Justiça (STJ) e por tantos outros tribunais pátrios, os quais, sob o manto da ponderação de valores e da supremacia destes em detrimento de restrições legais, preceitua que se deve excetuar a regra. Senão, vejamos:

2. Em situações reconhecidamente excepcionais, tais como a que se refere ao urgente fornecimento de medicação, sob risco de perecimento da própria vida, a jurisprudência deste Superior Tribunal de Justiça é reiterada no sentido do cabimento do bloqueio de valores diretamente na conta corrente do Ente Público (41).

Contudo, a pretexto do já exposto, é preciso que os magistrados deixem patente quais os critérios utilizados por eles para separar o joio do trigo. Ora, como saberemos quais casos merecem ser excetuados se não atendem à lei, tampouco às normas específicas de direito sanitário, quiçá ouvir os profissionais que atuam no sistema público de saúde, tornando a jurisprudência uma verdadeira área nebulosa. Qual o fiel da balança da insegurança jurídica?

Necessário se faz compreendermos o conceito de universalidade, de direito à saúde e da consequente obrigatoriedade do Estado em fornecer meios adequados para garantir a efetividade, os quais, muito embora sejam argumentos suficientes para se discutir o direito à concessão de determinado tratamento/medicamento, não o são para ignorar a execução cabível contra a Fazenda Pública.

As medidas aqui discutidas violam inúmeros preceitos fundamentais, dentre os quais podemos elencar: segurança orçamentária; competência do chefe do Executivo para 
executar o orçamento; independência entre os poderes; o princípio federativo; o regime de repartição de receitas tributárias e a preservação da isonomia entre os credores do Estado.

Estas ingerências na movimentação de recursos de uma programação para outra acarreta um desrespeito à vedação constitucional de alteração indireta da lei orçamentária, o que nos escrutínios de Gandra e Martins:

As programações orçamentárias são projetadas pelo Poder Executivo e aprovadas pelo Poder Legislativo, razão pela qual a lei orçamentária retrata um projeto que, em tese, exterioriza o desejo da sociedade de que seja aplicado da forma como foi aprovado. Ora, a mudança de programação por iniciativa do Executivo em sentido contrário à disposição constitucional representaria reduzir a lei orçamentária a singela sugestão de literatura jurídica, sem quaisquer outras funções que não de mero aconselhamento ao Executivo. A lei orçamentária perderia toda a sua finalidade se os programas aprovados pudessem ser afastados e substituídos pelo Poder Executivo em sua execução (42).

Não sendo permitido ao Executivo movimentar recursos de uma programação orçamentária para outra ou de um órgão para outro, sem prévia autorização legislativa, tampouco é dado ao Judiciário fazê-lo, sob pena de ofensa ao princípio da legalidade orçamentária, a teor do $\operatorname{art.1}^{\circ}$ e seguintes da Lei Complementar 101/2000 (43). Essas constrições de verbas públicas determinados pelos inúmeros órgãos da Justiça recaem indiscriminadamente em quantias à disposição do Estado, o que deságua no deslocamento (proposital ou não) de recursos vinculados a determinadas programações orçamentárias para outras ou de um órgão para outro, o que vai de encontro ao disposto no art. 167, V da CRFB, além de ferir a independência e a harmonia dos poderes, uma vez que interfere no planejamento e execução que compete ao Executivo, além da legitimidade do Legislativo em aprovar o orçamento (1) (43).

Não é difícil compreender o que Judiciário brasileiro está fazendo a largo, pois se apresenta como o único "detentor da verdade", capaz de dar a última palavra em qualquer tema, o que não interfere apenas na balança da justiça como naquela que equilibra a harmonia entre os poderes constituídos.

Malgrado os princípios atinentes ao orçamento, o nosso poder judiciário alça proporcionalidade/ponderação à categoria de princípios, cuja bandeira justifica toda sorte de decisões e, ainda que não se ignore o peso e a importância dos direitos em quaestio, é preciso pontuar que o direito à saúde não é o direito à esperança ad infinitum. 
Nas palavras de Marcel:

Para ser justo, deve-se notar, todavia, que a democracia, considerada não em seus princípios, mas em suas efetivas realizações, ajudou da maneira mais perigosa a encorajar a reivindicação em todos os seus aspectos, da exigência por direitos - e de fato trazer um espírito mercenário para todas as relações humanas. [...] Cada indivíduo reivindica desde o início desfrutar da mesma consideração e das mesmas vantagens que o seu próximo; e, de fato, seu respeito pessoal tende a se resolver em uma atitude que não é apenas defensiva, mas sempre reivindicando direitos de outros. Assim, ele considera abaixo de sua dignidade fazer qualquer coisa que seja por nada (44).

Destarte, inobstante não se ignore que as cortes pátrias estão pacificadas no tocante à possibilidade de bloqueio/arresto, premente uma releitura do tema, ouvindo-se todos aqueles que têm condição de contribuir ao deslinde salutar da questão, sendo viável inclusive utilizar da Arguição de Descumprimento de Preceito Fundamental 420 (número único: 4003063-17.2016.1.00.0000), ajuizada pelo Governo do Estado de Roraima, para tal desiderato . Brasil. Supremo Tribunal Federal. Arguição de Descumprimento de Preceito Fundamental 420. Número único: 4003063-17.2016.1.00.0000 (45).

\section{Considerações finais}

O Poder Judiciário, sob o pretexto de conferir efetividade às políticas públicas em saúde, vem desconsiderando a organização dos serviços, os conhecimentos e práticas de técnicos da área de forma sistemática e desenfreada, além das políticas governamentais com participação popular. Para tanto, agarra-se a argumentos, em tese, inquestionáveis, pois hasteia a bandeira da defesa dos direitos fundamentais.

Com essa postura, o Poder Judiciário passa ao largo de compreender que a atenção à saúde depende de políticas multissetoriais abrangentes, além de não analisar a viabilidade em pactuá-la dentro dos critérios construídos com fundamento nos Protocolos Clínicos e Diretrizes Terapêuticas (PCDT), limitando-se ao fornecimento de serviços e medicamentos, cuja efetividade é, no mínimo, questionável.

Se, por um lado, poderíamos argumentar que o pulular de ações de saúde reflete um maior acesso à justiça, todavia, sabemos que o acesso à justiça em nossa pátria nada gentil é ainda de per si um privilégio, sendo as concessões feitas pelo Judiciário um reforço do 
status quo. A excessiva judicialização dos serviços públicos de saúde traz malefícios, especialmente quando as decisões judiciais desconsideram o planejamento coletivo em favor da perspectiva individual, o que inevitavelmente causa transtornos e retardamento do atendimento dos demais usuários que aguardam atendimento regular no SUS.

Noutro giro, a utilização de bloqueios e sequestros judiciais são medidas flagrantemente inconstitucionais porque não somente agridem frontalmente o regime de execução contra a Fazenda Pública, máxime o regime de precatórios, mas também, as regras de planejamento, orçamento e finanças públicas.

Em face da anomia legislativa, a jurisprudência brasileira se consolidou no sentido da proteção constitucional absoluta à saúde, à vida e à dignidade da pessoa humana. Todavia, ao admitir a possibilidade de desrespeito dos outros comandos que informam e conformam o regime jurídico público, o Poder Judiciário inviabiliza o planejamento, orçamento e gestão.

O regime jurídico administrativo público, com todas as derrogações de ordem pública, basilado pelos maxi-princípios da indisponibilidade do interesse público e supremacia do interesse público sobre o privado, salvaguarda o Tesouro, garantindo que a implementação e expansão de políticas públicas ocorra por meios legais e éticos, em observância aos princípios encartados na cabeça do art. 37 da Magna Carta.

As decisões que determinam os bloqueios e sequestros de valores nas contas públicas, embora, eventualmente, corroboradas em segunda instância e por Tribunais Superiores, são absolutamente anômalas às previsões constitucionais e legislação infraconstitucional, máxime ao considerarmos, inclusive, a ocorrência de bloqueios ocorridos em contas bancárias particulares dos gestores públicos e servidores.

\section{Referências}

1. Brasil. Constituição da República Federativa do Brasil, 8 de outubro de 1988. Brasília: Senado Federal, 2014.

2. Vilaça DSS, Rey Filho M. A saúde além do Artigo 196 da Constituição de 1988. Coletânea direito à saúde: institucionalização. 2018, v. 2, p. 56-67.

3. Fleury S, Ouverney AM. Política de saúde: uma política social. Políticas e sistemas de saúde no Brasil. 2012, p. 25-58. 
4. Ferraz OLM, Vieira FS. Direito à saúde, recursos escassos e equidade: os riscos da interpretação judicial dominante. Dados. 2009, v. 52, p. 223-251. Disponível em: http://www.scielo.br/scielo.php?script=sci_arttext\&pid=S0011-52582009000100007\&lng =en\&nrm=iso [Acesso em 23.jul.2019].

5. Instituto Brasileiro de Geografia e Estatísticas. Disponivel em: https://www.ibge.gov.br/apps/populacao/projecao/ [Acesso em 01.ago.2019].

6. Conferência Internacional sobre cuidados primários de saúde. Declaração de Alma-Ata. Disponível em: http://cmdss2011.org/site/wp-content/uploads/2011/07/Declara\%C3\%A7 \%C3\%A3o-Alma-Ata.pdf [Acesso em 28.jul.2019].

7. Paim JS, Silva LMV. Universalidade, integralidade, equidade e SUS. Disponível em: http://periodicos.ses.sp.bvs.br/scielo.php?script=sci_arttext\&pid=s1518-18122010000 200002\&lng=pt\&nrm=iso [Acesso em 27.jul.2019].

8. Simon LC. Desafio: concretização do direito à saúde pública no Brasil. Coletânea direito à saúde: para entender a gestão do SUS. 2015. Disponível em: https://www.conass.org.br/ biblioteca/pdf/colecao2015/CONASS-DIREITO_A_SAUDE-ART_31.pdf [Acesso em 23.jul. 2019].

9. Medauar O. Direito Administrativo Moderno. 20ed. São Paulo: Editora Revista dos Tribunais, 2016.

10. Rolim LB, Cruz RSBLCC, Sampaio KJAJ. Participação popular e o controle social como diretriz do SUS: uma revisão narrativa. Disponível em: https://www.scielosp.org/article/ sdeb/2013.v37n96/139-147/ [Acesso em 29.jul.2019].

11. Paixão ALS. Reflexões sobre a judicialização do direito à saúde e suas implicações no SUS. Ciências saúde coletiva. 2019, v. 24, p. 2167-2172. Disponível em: http://www.scielo.br/scielo.php?script=sci_arttext\&pid=S1413-81232019000602167 [Acesso em 29 ago. 2019].

12. Xavier C. Judicialização da Saúde: Perspectiva crítica sobre os gastos da União para o cumprimento das ordens judiciais. Coletânea direito à saúde: dilemas do fenômeno da judicialização da saúde. 2018, v. 2, p. 52-61.

13. Paim P. Os passos do SUS: do apogeu à falência. A judicialização da saúde. In Coletânea direito à saúde: dilemas do fenômeno da judicialização da saúde, 2018, v. 2, p. 87-106.

14. Saldiva PHN, Veras M. Gastos públicos com saúde: breve histórico, situação atual e perspectivas futuras. Estudos Avançados. 2018, v. 32, p. 47-61. Disponível em: http://www.revistas.usp.br/eav/article/view/146437 [Acesso em 27.jul.2019]. 
15. Didier Jr. F. Notas sobre a garantia constitucional do acesso a justiça: $O$ princípio da direito de ação ou da inafastabilidade do Poder Judiciário. Revista de Processo. 2002, v.108, p. 23-31.

16. Organização das Nações Unidas. Declaração Universal dos Direitos Humanos. Disponível em: https://nacoesunidas.org/wp-content/uploads/2018/10/DUDH.pdf [Acesso em 25.jul.2019].

17. Organização dos Estados Americanos. Convenção Americana de Direitos Humanos. Disponível em: https://www.cidh.oas.org/basicos/portugues/c.convencao_americana.htm. [Acesso em 25.jul.2019].

18. Cappelletti M, Garth B. Acesso à Justiça. Porto Alegre: Sergio Antonio Fabris Editor; 1988, p 25.

19. Santos BS. Pela mão de Alice: o social e o político na pós-modernidade. 7.ed. Porto: Editora Afrontamentos, 1999.

20. Domingos LO, Rosa GFC. O direito fundamental e coletivo à saúde no contexto da judicialização. Cadernos Ibero-Americanos de Direito Sanitário. 2019, v. 8, p. 82-99.

21.Sarlet IW, Figueiredo MF. Algumas considerações sobre o direito fundamental à proteção e promoção da saúde aos 20 anos da Constituição Federal de 1988. Direito do Consumidor, 2008, p. 125-172. Disponível em: https://www.stf.jus.br/arquivo/cms/

processoAudienciaPublicaSaude/anexo/O_direito_a_saude_nos_20_anos_da_CF_coletan ea_TAnia_10_04_09.pdf [Acesso em 30.ago.2019].

22. Theodoro Jr. H. Curso de direito processual civil: teoria geral do direito processual civil e processo de conhecimento. 55.ed. Rio de Janeiro: Editora Forense, 2014.

23. Bueno CS. Curso sistematizado de direito processual civil: tutela jurisdicional executiva. 7.ed. São Paulo: Editora Saraiva, 2014.

24. Abelha M. Manual de Execução Civil. 5.ed. Rio de Janeiro: Forense; 2015.

25. Brasil. Código de Processo Civil, 16 de março de 2015. Brasília: Senado Federal, 2017.

26. Lourenço H. Manual de direito processual civil. 2.ed. Rio de Janeiro: Editora Forense, 2013.

27. Nogueira RLN, Andrade MD. Responsabilidade do gestor público e a judicialização da saúde no contexto do Estado do Ceará. Quaestio luris. 2018, v. 11, Rio de Janeiro, p. 19121940. 
28. Ariquemes. $2^{\mathrm{a}}$ Vara Cível da Comarca de Ariquemes. Tribunal de Justiça de Rondônia. Processo de Cumprimento de Sentença no: 7006028-74.2017.8.22.0002. Requerente: Ministério Público do Estado de Rondônia. Requerido: Estado de Rondônia.

29. Brasil. Lei o 8.080, 19 de setembro de 1990. Dispõe sobre as condições para a promoção, proteção e recuperação da saúde, a organização e o funcionamento dos serviços correspondentes e dá outras providências. Brasília, 19 de setembro de 1990. Disponível em: http://www.planalto.gov.br/ccivil_03/leis//8080.htm [Acesso em 21.jul.2019].

30. Brasil. Tribunal de Contas da União. Acórdão 1787. 2017. Relator Bruno Dantas.

31. Hecktheuer PA, Castro RV, Hecktheuer FR. Os impactos da judicialização da saúde no Estado de Rondônia no período de 2010 a 2015 e a previsão de gastos para o biênio 2016/2017. Revista Eletrônica Direito e Política, Programa de Pós-Graduação Stricto Sensu em Ciência Jurídica da UNIVALI. 2018, v. 13: 792-823. Disponível em: www.univali.br/direitoepolitica [Acesso em 22.jul.2019].

32. Brasil. Decreto no 7.508, de 28 de junho de 2011. Regulamenta a Lei no 8.080, de 19 de setembro de 1990, para dispor sobre a organização do Sistema Único de Saúde - SUS, o planejamento da saúde, a assistência à saúde e a articulação interfederativa, e dá outras providências. Brasília, 28 de junho de 2011. Disponível em: http://www.planalto.gov.br/ccivil_03/_Ato2011-2014/2011/Decreto/D7508.htm. [Acesso em 26.jul.2019].

33. Ribeiro IV. A efetivação da participação popular direta como mecanismo de fortalecimento da democracia. Advocacia Pública e desenvolvimento: uma homenagem aos 30 anos da Procuradoria Geral do Estado de Rondônia. Rio de Janeiro: Lumen Juris, 2018, p. 91-109.

34. Relatório de auditoria do Tribunal de Contas da União. TC 009.253/2015-7. Disponível em: https://portal.tcu.gov.br/biblioteca-digital/auditoria-operacional-sobre-judicializacao-dasaude.htm [Acesso em 20.jul.2019].

35. Barroso LR. Neoconstitucionalismo e constitucionalização do Direito: o triunfo tardio do direito constitucional no Brasil. Revista de Direito Administrativo FGV. 2005, v. 240, p. 1-42. Disponível em: http://bibliotecadigital.fgv.br/ojs/index.php/rda/issue/view/2473 [Acesso em 25.jul. 2019].

36. Marinoni LG. Novas linhas do processo civil. 3.ed. São Paulo: Malheiros editores,1999.

37. Ramos ES. Ativismo judicial: parâmetros dogmáticos. São Paulo: Saraiva, 2010.

38. Streck LL. Verdade e Consenso: Constituição, hermenêutica e teorias discursivas. 4.ed. São Paulo: Saraiva, 2012. 
39. Brasil. Decreto-Lei no 4.657, de 4 de setembro de 1942. Lei de Introdução às normas do Direito brasileiro. Rio de Janeiro, 4 de setembro de 2000. Disponível em: http://www.planalto.gov.br/ccivil_03/decreto-lei/del4657.htm [Acesso em 30 ago. 2019].

40. Streck LL. O que é isso: as garantias processuais penais? 2ed. Porto Alegre: Livraria do Advogado, 2012.

41. Brasil. Superior Tribunal de Justiça. Recurso Especial ํo 766.480/RS. Recorrente: Estado do Rio Grande do Sul. Recorrido: Fernando Scremim. Relator: Ministro Teori Zavascki. Brasília: 20 set 2005. Lex: jurisprudência do STJ, T1. Primeira Turma. Brasília: 197: p. 139.

42. Bastos CR, Martins IG. Comentários à Constituição do Brasil. São Paulo: Saraiva, 2001.

43. Brasil. Lei Complementar ํㅜ 101, de 4 de maio de 2000. Estabelece normas de finanças públicas voltadas para a responsabilidade na gestão fiscal e dá outras providências. Brasília, 4 de maio de 2000. Disponível em: http://www.planalto.gov.br/ccivil_03/leis/lcp/lcp101.htm [Acesso em 25 jun. 2019].

44. Marcel G. Homo Viator: Introduction to the Metaphysic of Hope. South Bend: St. Augustines Press, 1962, p. 56.

45. Brasil. Supremo Tribunal Federal. Arguição de Descumprimento de Preceito Fundamental 420. Número único: 4003063-17.2016.1.00.0000.

Ribeiro IV, Costa AV, Sena HGN. A inconstitucionalidade do manejo do sequestro e do bloqueio de contas da Fazenda Pública como mecanismo satisfativo. Cadernos Ibero-Americanos de Direito Sanitário. 2019 jul./set.; 8(3): 131 -151. 